\title{
Fracture Mechanics Analyses of Subsurface Defects in Reinforced Carbon-Carbon Joggles Subjected to Thermo-Mechanical Loads
}

\author{
Norman F. Knight, Jr. ${ }^{1}$ \\ General Dynamics Information Technology, Chantilly, Virginia \\ Ivatury S. Raju ${ }^{2}$ \\ NASA Langley Research Center, Hampton, Virginia \\ Kyongchan Song ${ }^{3}$ \\ ATK Space Division, Hampton, Virginia
}

\begin{abstract}
Coating spallation events have been observed along the slip-side joggle region of the Space Shuttle Orbiter wing-leading-edge panels. One potential contributor to the spallation event is a pressure build up within subsurface voids or defects due to volatiles or water vapor entrapped during fabrication, refurbishment, or normal operational use. The influence of entrapped pressure on the thermo-mechanical fracture-mechanics response of reinforced carbon-carbon with subsurface defects is studied. Plane-strain simulations with embedded subsurface defects are performed to characterize the fracture mechanics response for a given defect length when subjected to combined elevated-temperature and subsurfacedefect pressure loadings to simulate the unvented defect condition. Various subsurface defect locations of a fixed-length substrate defect are examined for elevated temperature conditions. Fracture mechanics results suggest that entrapped pressure combined with local elevated temperatures have the potential to cause subsurface defect growth and possibly contribute to further material separation or even spallation. For this anomaly to occur, several unusual circumstances would be required making such an outcome unlikely but plausible.
\end{abstract}

\section{Introduction}

卫 he overview of the Space Shuttle Orbiter, shown in Figure 1 and described in Ref. 1, depicts the structural layout of the wing interior structure as well as representative wing-leading-edge (WLE) panels and T-seal. The reinforced carbon-carbon (RCC) material along the Space Shuttle Orbiter's wing-leading edges serves as part of the overall thermal protection system [1]. The leading edge of each wing has twenty-two RCC panel/T-seal sets that are designed to provide aerodynamic performance and to provide thermal protection on entry.

During the installation process, the adjacent RCC panels are installed onto the WLE front spar of each wing of the Space Shuttle Orbiter. A gap between adjacent WLE panels facilitates the installation process and accommodates thermal expansion during a mission. T-seal components are installed between adjacent panels to

${ }^{1}$ Principal Subject Matter Expert, Structural Mechanics, Fellow AIAA, Fellow ASME.

${ }^{2}$ NASA Technical Fellow for Structures, NASA Engineering and Safety Center, Fellow AIAA, Member ASME, Member ASCE.

${ }^{3}$ Structural Analyst, Member AIAA. 
cover the gap along the WLE surface. A cross-sectional view of two adjacent panels and the corresponding T-seal is shown in Figure 2 giving an overall perspective. The outer mold line (OML) is exposed, while the inner mold line (IML) is on the interior of the panels. The inboard and outboard sides of adjacent WLE panels and the corresponding flanges of the T-seal close this gap between adjacent panels. The surface edges along the inboard and outboard edges of each WLE panel near the panel ribs exhibit local changes in curvature and thickness, and these regions are referred to as joggle regions. Both regions exhibit changes in thickness and curvature. The outboard edge of each panel has a lock-side feature, shown for Panel 9 in Figure 2, for direct mating with a T-seal during the assembly process. The inboard edge of each panel has a slip-side feature, shown for Panel 10 in Figure 2, to accommodate thermal expansion of the T-seal during entry heating.

RCC is a composite laminated material. The base composition for RCC is a lamina of phenolic resin impregnated plain-weave carbonized rayon fabric, and during fabrication, the outer surfaces of the carbon-carbon substrate are converted to silicon carbide (SiC) [1, 2]. The resulting material system is then referred to as coated RCC wherein the outer layers are SiC coating and the interior material is carbon-carbon substrate. Within the coating material, craze cracks develop during fabrication and manufacture due in part to the thermal mismatch between the coating and the substrate. A cross-sectional view of a typical RCC slip-side joggle region of a wingleading-edge (WLE) panel with craze cracks and a subsurface defect is shown in Figure 3. In addition, subsurface defects with material separation, such as the one shown in Figure 3, have been detected using infrared (IR) thermography in combination with microscopy examinations [3].

As the temperature increases on entry, any volatiles within a subsurface defect of the RCC material could potentially get trapped and generate high pressures if the material is unvented and has a closed-volume [4]. For the elevated temperatures experienced during entry, entrapped volatiles and water vapor will expand, and if a vent path exists, the resulting pressure will be vented or outgassed. Outgassing from voids, craze cracks, and/or subsurface defects could occur, and if the venting rate is limited, the entrapped pressure could increase and potentially contribute to spallation. Material testing indicated that RCC exhibits permeability [5], and it is unlikely that entrapped pressure build ups occur. Preliminary results from some exploratory fracture mechanics simulations indicated that such entrapped pressure could provide a plausible mechanism for subsurface defect growth and possible spallation if volatiles or water vapor are present within the subsurface defect and if subsurface-defect pressure can be contained (i.e., unvented defect assumption). For this anomaly to occur, several unusual circumstances would be required making such a response plausible although rare.

The paper summarizes the fracture mechanics analysis effort [6] for combined thermo-mechanical loading that was performed to demonstrate the plausibility of this scenario. In this paper, two-dimensional (2D) plane-strain modeling and analyses performed to simulate the influence of entrapped pressure on the thermo-mechanical fracture mechanics response of the RCC slip-side joggle region are presented. The plane-strain modeling and analyses details for the entrapped pressure simulations are discussed. Then, the fracture mechanics analyses and mixed-mode fracture criterion is described. Finally, numerical results are discussed for subsurface defects with vented and unvented assumptions.

\section{Plane-Strain Modeling and Analysis}

Thermo-mechanical elastic stress analyses [7, 8] have indicated that a 2D plane-strain analysis would represent the fundamental thermo-mechanical response characteristics of a WLE panel's slip-side joggle region. In addition, the plane-strain solutions represent bounding cases for the fracture mechanics results (i.e., the three-dimensional (3D) fracture results for part-through defects are less severe than those obtained from the plane-strain assumptions [9]). This section describes the slip-side joggle configuration, the finite element (FE) model used in the fracture analyses, and the modeling approach for substrate defects.

\section{Slip-Side Joggle Configuration:}

The cross-sectional configuration of the slip-side joggle used in these analyses is shown in Figure 4 to illustrate the nomenclature used. The joggle configuration is taken from the computer-aided design (CAD) model of a 
representative WLE panel near the panel's apex. Local spanwise changes in curvature and thickness in the joggle region are evident from this figure. The yellow area in Figure 4 denotes the substrate material. The blue areas in Figure 4 denote the SiC conversion zone on the outer mold line (OML) and inner mold line (IML) surfaces. These conversion zones, often called SiC coating layers, are generally non-uniform in thickness and are not actually discrete layers of $\mathrm{SiC}$ material. In these analyses, however, the $\mathrm{SiC}$ coating is assumed to have uniform thickness, and a sharp interface exists between the coating and the substrate regions. The red curve in Figure 4 denotes a subsurface defect near the joggle shoulder that is entirely within the substrate material - a substrate defect.

A subsurface defect location index is also indicated in Figure 4 (e.g., values include $-1,0,+1$, etc.). This index is simply a numbering system to identify a particular craze crack along the OML surface within the analysis model. For these simulations, the craze crack labeled Location 0 is near the top of the joggle shoulder on the OML surface where the transition from the flat acreage region to the curved joggle begins. Positive values of the index refer to craze cracks along the joggle, while negative values indicate craze cracks towards the acreage region. For example, Location -1 is one craze-crack spacing towards the acreage region from Location 0 as indicated in Figure 4, while Location +1 is one craze-crack location along the joggle itself.

In these coating regions (i.e., the blue areas in Figure 4), craze cracks initially develop during the fabrication process due to the thermal mismatch between the coating material and the carbon-carbon substrate material. These craze cracks have been observed, on average, to have a spanwise spacing in the panel acreage region that is twice the spacing near the joggle region. In the present analyses, uniform craze-crack spacing is modeled on the OML and IML surfaces, and the craze cracks are always oriented normal to the joggle outer surfaces. The craze cracks in the coating material are explicitly represented in the FE model. The lines normal to the outer surfaces in the blue regions (coating material) represent craze cracks that create islands of coating material. These islands may interact due to thermo-mechanical loading, and hence, contact between adjacent coating island edges is monitored during the analysis.

Each transverse craze crack in the coating is modeled by defining pairs of coincident nodes along each crazecrack edge and assigning contact conditions to the craze-crack edges. These craze cracks are free to open or close due to thermo-mechanical loading during the analysis. When they close, interaction between adjacent craze-crack edges occurs for interface defects. The smoothness (or roughness) of the craze-crack surfaces is simulated by specifying a non-zero coefficient of friction $\mu$ on these edges to account for possible craze-crack edge interaction. For perfectly smooth edges, $\mu$ equals zero. For substrate defects, the craze-crack edges do not displace independently but move with the thin ligament of substrate material just below the craze crack. Thus, friction has no effect for the substrate defects considered in this report.

\section{Subsurface Defect:}

Subsurface defects, such as the one shown in Figure 5, are embedded within the plane-strain FE models. In all cases, the subsurface defect is implemented in a manner similar to that used for the explicit craze-crack modeling. Pairs of coincident nodes are introduced along both free surfaces of the defect. The defect surfaces are also assumed to be frictionless (i.e., perfectly smooth, $\mu=0$ ); however, surface-to-surface contact is monitored to prevent interelement penetration during the analysis.

A subsurface defect within the substrate material extending from Location -1.5 to +1.5 (Case -1.5 ) is analyzed as a representative subsurface defect based on the observed coating spallation events. This type of defect is also referred to as a substrate defect as it is located completely within the substrate material (see Figure 5). The left tip of the defect is towards the acreage region, and the right tip of the defect is towards the joggle region. The subsurface defect is located one element below the coating-substrate material interface and is referred to as a substrate defect. A substrate defect near the coating-substrate material interface is observed in the photo-micrographs and hence is modeled in the fracture mechanics analysis. The spanwise location of the defect will be varied along the slip-side joggle region to determine its influence on the fracture mechanics response, i.e., Locations - $1,-0.5$, etc. are considered. 
The bounding surfaces of the substrate defect are pressurized due to the entrapped volatiles or water vapor no leak-path, craze-crack venting, or material permeability is assumed or considered. In addition, the internal defect pressure is assumed to be independent of the volume defined by the deflected (separated) defect surfaces when pressurized. Note that the actual origin and magnitude of such internal pressure, as well as validity of a closed volume assumption, are still undetermined [4]. The defect internal pressure is assumed to be uniform over all free surfaces of the substrate defect, and its value is incrementally increased during the analysis and intermediate solutions obtained. For each FE solution, the fracture mechanics response is evaluated.

\section{Modeling Details:}

The joggle region of the plane-strain FE model developed for a typical local RCC slip-side joggle region is shown in Figure 5. The FE model of a cross-sectional slice through the slip-side joggle region has 6,623 nodes and 6,244 4-node plane-strain elements. The CPE4I 2D 4-node plane-strain quadrilateral element with incompatible modes available in ABAQUSTM/Standard ${ }^{4}[10]$ is used in the thermo-mechanical stress analyses. The left edge of the FE model is within the acreage region, which has a uniform thickness of 19 plies. Just past midway, the slip-side joggle region is reached, which exhibits a thickness increase to 22 plies as well as different radii of curvature on the OML and IML surfaces. At the far right, the thickness becomes uniform again at 19 plies. Along the length of the model (i.e., spanwise), the element spacing is related to the assumed craze-crack spacing. Eight 4-node plane-strain elements are between each craze crack. The number of elements through the total thickness is constant all along the span (i.e., twenty-eight 4-node elements).

The mechanical properties for the coating and substrate materials are given in Ref. 11. As discussed previously, the plane-strain models explicitly include the transverse craze cracks in the IML and OML coating layers that extend from the outer surfaces to the substrate-coating interface through the coating layer. Hence, these coating models are referred to as island coating models. ${ }^{5}$ The material of these islands is assumed to be in-situ sintered SiC, and the temperature-dependent isotropic properties at-temperature are used in these analyses. The substrate material is treated as uncoated RCC or carbon-carbon, and the temperature-dependent transversely isotropic properties attemperature are used. The at-temperature approach for material modeling provides upper bound values for the fracture response of subsurface defects [9]. The coefficients of thermal expansion are secant-based values defined with the given reference temperature. Thermo-mechanical analysis results of RCC structures are significantly influenced by the stress-free temperature (SFT) of the material (e.g., see Ref. 3). The SFT has been defined as the temperature at which a flat RCC specimen exhibits no strain based on an average measured craze-crack opening. An analysis process described in Ref. 3 to determine the SFT analytically is based on a repeating-unit, plane-strain model of a flat RCC acreage region. Using a repeating-unit, plane-strain model of an acreage region with craze cracks, the best-estimate, effective SFT value of $1350^{\circ} \mathrm{F}$ is determined. This best-estimate, effective SFT value is used throughout the present study, unless otherwise stated. The SFT value is for the coated RCC system and is assumed to be the same for both coating and substrate.

\section{Analysis Process:}

The thermo-mechanical stress analyses are performed using the 2D plane-strain FE models just described. Because a temperature-dependent, bi-modulus transversely isotropic material model is not presently available as a standard material model within ABAQUSTM/Standard, material data for different thermal conditions are defined in one of two ways. First, existing elastic single-modulus material models within ABAQUSTM/Standard can be used provided a uniform thermal condition is applied and an a priori understanding of the response is known; that is, for example under peak-heating entry conditions, the coating is in compression and the substrate is in tension. Hence,

\footnotetext{
${ }^{4}$ ABAQUS ${ }^{\mathrm{TM}} /$ Standard is a registered trademark of Dassault Systèmes Simulia Corp.

${ }^{5}$ Island coating models differ from homogeneous coating models in that homogeneous models smear the effect of the craze cracks out by using different elastic moduli for tension (zero or near-zero modulus) and compression rather than explicitly including the craze cracks in the FE model and using contact conditions.
} 
appropriate tension or compression material properties (i.e., single modulus approach) are defined for the coating and substrate constituent materials, and an existing elastic material model within ABAQUS ${ }^{\mathrm{TM}}$ is used. Alternatively, a user-defined material model is needed that directly accounts for local temperature variations as well as the bimodulus behavior of the RCC material. In both cases, the material property data may be specified as temperaturedependent or as values at the final temperature (i.e., at-temperature properties). When temperature-dependent properties are specified, solutions obtained during the nonlinear solution process provide intermediate thermomechanical stress results for temperatures other than the final temperature. When at-temperature properties are specified, only the thermo-mechanical solution for the final temperature has the appropriate material properties. For these analyses of uniform elevated temperature conditions, only the at-temperature material modeling approach is used.

Once the nonlinear finite element analysis is completed using ABAQUS ${ }^{\mathrm{TM}} / \mathrm{Standard}$, the thermo-mechanical stress state is then evaluated. When subsurface defects are included in the analysis model, nodal displacements and internal forces are extracted from the FE results and used in the fracture mechanics calculations to evaluate the defect driving forces at both defect tips. After the defect driving forces are computed, a mixed-mode fracture criterion is evaluated.

\section{Fracture Criteria}

The fracture mechanics response is quantified using the total strain energy release rate at the defect tip. The total strain energy release rate $G_{T}$ has units of energy per unit area. The total energy release rate is evaluated by computing the energy release rates for the individual fracture modes (i.e., for plane strain, $G_{I}$ for the opening mode and $G_{I I}$ for the shearing mode) and then summing the individual contributions. This $G_{T}$ value is also called the total defect driving force where the units are force per unit defect extension. Hence, the fracture mechanics results are presented herein as the total defect driving force or $G_{T}$. The resistance of the material to the defect growth is related to the toughness of the material and is referred to as the resistance or $R$.

The fracture mechanics analyses are performed using ABAQUSTM/Standard FE code [10] to obtain displacements and internal forces, and then separate fracture mechanics calculations are performed based on the FE results. Nonlinear, large-displacement solution procedures are used to account for any geometric nonlinearities and to simulate the contact condition between the craze-crack edges and between the free surfaces of the substrate defect. Using the elastic results, the total defect driving force (total strain energy release rate, $G_{T}$ ) is calculated using the Virtual Crack-Closure Technique (VCCT) (e.g., see Refs. 12-14). The VCCT approach is still valid in these cases even though friction is included along the craze-crack surfaces; since the VCCT calculations are performed at the subsurface defect tips and away from the craze cracks, linear elastic fracture mechanics assumptions still apply.

\section{Mixed-Mode Fracture Criterion:}

In three-dimensional fracture mechanics analyses, the total defect driving force has three components associated with the three modes of fracture (Mode I or the opening mode, Mode II or the shearing mode, and Mode III or the tearing mode). For the plane-strain analyses, only the opening and shearing fracture modes are evaluated. When both fracture modes are present, a mixed-mode fracture criterion is needed to determine whether the defect is stable (defect unlikely to extend or grow) or unstable (defect likely to extend or grow in a catastrophic manner). Typically, a curve fit of the mixed-mode fracture data is developed as shown in Figure 6 to define the critical fracture toughness $G_{c}$ for the mixed-mode case. This critical value is also referred to as the mixed-mode resistance $R$.

The Benzeggagh-Kenane (B-K) criterion [15] for 2D plane strain is given by

$$
\frac{G_{T}}{G_{I c}+\left(G_{I I c}-G_{I c}\right)\left(\frac{G_{I I}}{G_{T}}\right)^{m}}=\frac{G_{T}}{G_{I c}+\left(G_{I I c}-G_{I c}\right) \beta^{m}}=\frac{G_{T}}{R_{m}} \geq 1
$$


and is used as the mixed-mode fracture criterion for 2D plane strain. Here, $G_{I c}$ and $G_{I I c}$ represent the material toughness values (also called critical strain energy release rates) for the opening and shearing fracture modes, respectively. Different test configurations were used in the RCC fracture testing [16] to determine $G_{I C}$ and $G_{I I c}$. In addition, $G_{I}$ and $G_{I I}$ represent the defect driving forces (i.e., strain energy release rates) for the opening and shearing fracture modes, respectively. The parameter $\beta$ represents the ratio of the mode II defect driving force and the total defect driving force and is often referred to as the mode mixity ratio. The $G_{T}$ represents the total defect driving force (i.e., total strain energy release rate) given by

$$
G_{T}=G_{I}+G_{I I}
$$

The denominator of Equation 1 represents the B-K resistance $R_{m}$ to the defect driving force $G_{T}$. When the ratio of the total defect driving force $G_{T}$ to the B-K resistance $R_{m}$ for a given value of $m$ is less than unity, the defect is said to be stable and defect growth is unlikely. When the ratio equals or exceeds unity, the defect is said to be unstable and catastrophic defect growth is likely. This ratio, Equation 1, represents the B-K mixed-mode fracture criterion.

The fracture mechanics response depends on the exponent $m$ of the B-K mixed-mode fracture criterion given in Equation 1. A typical mixed mode $G_{c}$ curve as a function of the mode mixity ratio $\beta$ is given in Figure 6 . A value of $m=1$ results in a linear fit between $G_{I c}$ and $G_{I I c}$ as shown by the green dotted lined in Figure 6. However, values of $m>1$ result in a lower value of $G_{c}$ than that denoted by the linear approximation (i.e., $m=1$ ). For polymeric composites, $m$ takes a value in the range of 2 to 4 . The red curve in Figure 6 shows the variation of $G_{c}$ as a function of the mode mixity ratio, $\beta$. As indicated in Figure 6, a large portion of the response is dominated by a Mode I response, in the range $0 \leq \beta \leq \bar{\beta}$. The mixed mode dominated region is the range $\bar{\beta} \leq \beta \leq 1$, where $\bar{\beta}$ is typically 0.7 or 0.8 . A value of two was selected as the value of the exponent $m$. Hence, the resistance to the defect driving force is then denoted as $R_{m=2}$. In the present analyses, the B-basis fracture toughness values are used as they provide a smaller value for $R_{m=2}$, which is conservative.

\section{Numerical Results and Discussion}

Numerical results are presented in this section for a fixed-length substrate defect along the slip-side joggle region. Prior to using the present model for the unvented, entrapped pressure simulations, the peak-heating entry conditions for the vented case were evaluated and compared for consistency with previous fracture mechanics results for thermal loading only [9]. The analysis approach for the entrapped pressure simulations includes examining a single subsurface defect length at different spanwise locations along the joggle (see Figure 7). Attemperature material properties are used in all simulations, and the best-estimate SFT of $1350^{\circ} \mathrm{F}$ is assumed. All subsurface defects considered are assumed to be 0.375 inches in length along the span and located at a depth of about 0.007 inches below the coating-substrate material interface.

\section{Vented Defect Assumption - Thermal Loading Only}

A comparison is presented in Figure 8 of the total defect driving force $G_{T}$ (yellow bars) and the defect resistance $R_{m=2}$ (green bars) for each defect location by case number. The defect tip is predicted to be stable as long as the total defect driving force is less than the resistance (i.e., the B-K criterion). From Figure 8, the fracture behavior is known based on the value of the defect resistance $R_{m=2}$ : a Mode I response is observed when $R_{m=2}$ approaches $G_{I c}$, and a Mode II response is observed when $R_{m=2}$ approaches $G_{\text {IIc }}$. The B-basis fracture toughness values are used in the resistance calculations. Results for the different spanwise defect locations are presented in Figure 8a for the left tip and in Figure $8 \mathrm{~b}$ for the right tip and indicate that the fracture response of both defect tips is dominated by Mode I behavior (i.e., $R_{m=2}$ is nearly equal to $G_{I c}$ ). When both defect tips are within the acreage region (Case -3.5 ), the defect is stable for the thermal loading condition alone. As the defect is moved along the joggle, the left tip becomes unstable as it approaches the joggle shoulder (Case -1 ), while the right tip is unstable or nearly unstable for all locations except Case -3.5 and Case -0.5 . 
These vented defect results for the peak-heating entry temperature loading alone (i.e., $2900^{\circ} \mathrm{F}$ ) are consistent with the results reported previously (i.e., Cases -2 and -1 are identical to those given in Ref. 9). Except for Case -0.5 where the left defect tip is very near the joggle shoulder, the total defect driving force for the right tip of the defect is higher than that for the left tip. Defect tips at or near the joggle shoulder region are predicted to be unstable for the assumptions used in the analysis (i.e., $T_{\text {Final }}=2900^{\circ} \mathrm{F}, \mathrm{SFT}=1350^{\circ} \mathrm{F}$, and B-basis toughness values).

\section{Unvented Defect Assumption - Combined Loading}

For the combined loading analyses, the substrate defect is assumed to be unvented and a two-step analysis process is employed as illustrated in Figure 9a. The first analysis step is to impose the thermal loading ( $\left.T_{\text {Final }}\right)$. The results from the first step establish whether the defect tips are stable or unstable for the thermal loading alone (see Figure 9b). The green line along the abscissa in Figure 9b represents different possible solutions for different final temperatures and zero subsurface-defect pressure. For this example, a single final temperature is applied as the thermal loading that resulted in a value of about 0.5 for the B-K fracture criterion. Note that only defects that are stable can carry additional defect-opening loading. The second analysis step is to impose a uniform subsurfacedefect pressure $p$ on the free surfaces of the substrate defect (see Figure 9a) while retaining the uniform thermal loading. The magnitude of the pressure loading is incrementally increased up to some specified maximum value (i.e., 2000 psi). Once the second analysis step is completed, the FE results are interrogated, the defect driving forces are calculated using VCCT, and the mixed-mode fracture criterion is evaluated. For each pressure increment, the B$\mathrm{K}$ fracture criterion is evaluated resulting in the red curve shown in Figure 9b. The yellow vertical line (i.e., B-K criterion equal to unity) is the boundary between stable defect response to the left and unstable defect response to the right. The intersection of the red curve with the yellow vertical line defines the critical entrapped pressure value.

\section{Peak-Heating Entry Temperature Conditions:}

The combined loading case for the unvented assumption imposes peak-heating entry temperature as the final temperature $\left(T_{\text {Final }}=2900^{\circ} \mathrm{F}\right)$ in the first analysis step, and then adds on the entrapped pressure loading for the second analysis step. For this case, the material properties are defined at the peak-heating entry temperature condition $\left(2900^{\circ} \mathrm{F}\right)$, the SFT is taken as $1350^{\circ} \mathrm{F}$, and the B-basis fracture toughness values are used in the B-K fracture criterion. When the applied temperature is above the SFT, the fracture response has been shown to be dominated by Mode I behavior [9], and in some cases, the total defect driving force may exceed the Mode I fracture toughness. In combining this thermal condition with an entrapped pressure, the fracture response continues to be dominated by Mode I behavior as the pressure increases.

The entrapped pressure as a function of the B-K fracture criterion $\left(G_{T} / R_{m=2}\right)$ is shown in Figure 10 for different spanwise defect locations along the joggle. Results are shown in Figure 10a for the left tip and in Figure 10b for the right tip. The results for the peak-heating entry temperature thermal loading alone are indicated along the abscissa in Figure 10 and indicate the sensitivity of the fracture response to defect location for peak-heating entry conditions consistent with the results reported in Ref. 9. The critical entrapped pressure for a given defect location occurs when $G_{T} / R_{m=2}$ equals unity (red circles on the yellow vertical line in the figure). For the left tip, Cases -0.5 and -1 indicate that the defect is unstable due to thermal loading alone. As the left tip is moved farther into the acreage, the critical pressure increases. For the right tip, only Case -3.5 (both defect tips located in the acreage) exhibits a stable condition after application of the peak-heating entry temperature loading. The critical entrapped pressure for Case -3.5 is 300 psi for the right tip to satisfy the B-K fracture criterion (i.e., for the defect to become unstable).

A summary of the critical entrapped pressures as the defect tip is moved spanwise along the joggle region is shown in Figure 11 for the peak-heating entry temperature case. The blue curve represents the values for the left tip, and the red curve represents the values for the right tip. Location 0 corresponds to the joggle shoulder and is highlighted in yellow in this figure. The lowest critical entrapped pressure is $30 \mathrm{psi}$, and this value is obtained when the 0.375 -inch-long substrate defect is located between defect location index values of -1.5 and +1.5 . However, the right tip of this defect is already unstable at the peak-heating entry temperature. The only defect location where both tips are stable prior to the application of the entrapped pressure is Case -3.5 (i.e., both defect tips are in the acreage 
region) with a corresponding critical pressure value of 300 psi for the right tip (see Figure 11). The critical pressure value decreases for both defect tips as they are moved in the direction of the joggle.

\section{Intermediate Elevated-Temperature Conditions:}

While a peak-heating entry temperature of $2900^{\circ} \mathrm{F}$ was analyzed previously, this peak temperature represents the maximum expected temperature during entry. Many of the WLE panels experience OML entry temperatures well below this maximum value. The influence of entrapped pressure (unvented substrate defect) on the fracture response of a 0.375 -inch-long substrate defect at different spanwise locations along the joggle is examined for intermediate elevated-temperature values in this section. Each combined loading case imposes an elevated temperature on the plane-strain model as the final temperature in the first analysis step, and then adds on the entrapped pressure loading for the second analysis step based on the unvented substrate defect assumption. The material properties are defined at each elevated-temperature value, and the SFT is taken as $1350^{\circ} \mathrm{F}$. The B-K fracture criterion is evaluated using both the B-basis and average fracture toughness values.

\section{Case -3.5 Response:}

The first case to examine is Case -3.5 that has both substrate defect tips within the acreage region as shown in Figure 7. The entrapped pressure as a function of the B-K fracture criterion $\left(G_{T} / R_{m=2}\right)$ is shown in Figure 12 for both defect tips. Results are shown in Figure 12a for the left tip and in Figure 12b for the right tip. The critical entrapped pressure for a given elevated-temperature value occurs when $G_{T} / R_{m=2}$ equals unity (red circles on the yellow vertical line in the figure). The smallest critical pressure for any temperature evaluated is $210 \mathrm{psi}$ for either defect tip to satisfy the B-K fracture criterion (i.e. for the defect to become unstable). As the final temperature value increases, the general trend is for both defect tips to exhibit similar Mode I fracture behavior.

A summary of the critical entrapped pressures as a function of the elevated-temperature value is shown in Figure 13 for Case -3.5. The blue curve represents the values for the left tip, and the red curve represents the values for the right tip. The solid curves use the B-basis fracture toughness values, while the dashed curves use the average fracture toughness values (see Ref. 15). Location 0 corresponds to the joggle shoulder, and the stable defect region is highlighted in yellow in this figure. As the temperature increases to $2500^{\circ} \mathrm{F}$, the entrapped pressure value needed to satisfy the B-K fracture criterion also increases up to a value of 340 psi. The right tip, which is closer to the joggle shoulder, is the dominant defect tip at the higher temperatures.

\section{Case -2.5 Response:}

The second case to examine is Case -2.5 that has left substrate defect tip within the acreage region and the right tip just beyond the joggle shoulder as shown in Figure 7 . The entrapped pressure as a function of the B-K fracture criterion $\left(G_{T} / R_{m=2}\right)$ is shown in Figure 14 for both defect tips. Results are shown in Figure 14a for the left tip and in Figure 14b for the right tip. The critical entrapped pressure for a given elevated-temperature value occurs when $G_{T} / R_{m=2}$ equals unity (red circles on the yellow vertical line in the figure). For this case, the fracture response of the left and right tips is different. The left tip is nearly insensitive to increasing temperature values as shown in Figure 12a, and the fracture response is dominated by Mode I behavior. However, the right tip, which is just beyond the joggle shoulder, exhibits a different character. For temperatures below $2500^{\circ} \mathrm{F}$, the right tip exhibits a mixed-mode response. For temperatures much above $2500^{\circ} \mathrm{F}$, the right tip is critical (unstable) without any pressure loading, and the fracture response, while still mixed mode, approaches a Mode I behavior. At $2500^{\circ} \mathrm{F}$, an entrapped pressure of only 30 psi causes the right tip to become unstable. At $1500^{\circ} \mathrm{F}$, an entrapped pressure of 300 psi is needed for the right tip to become unstable.

A summary of the critical entrapped pressures as a function of the elevated-temperature value is shown in Figure 15 for Case -2.5 . The blue curve represents the values for the left tip, and the red curve represents the values for the right tip. The solid curves use the B-basis fracture toughness values, while the dashed curves use the average fracture toughness values (see Ref. 15). The left tip is the dominant defect tip for elevated temperature below $1500^{\circ} \mathrm{F}$, and the fracture response is dominated by a Mode I behavior. The right tip is the dominant defect tip at the 
higher temperatures and exhibits a mixed-mode fracture response. The lowest critical entrapped pressure is $270 \mathrm{psi}$ for temperatures from room temperature (RT) up to $1500^{\circ} \mathrm{F}$, and the left tip dominates the response. As the temperature increases above $1500^{\circ} \mathrm{F}$, the entrapped pressure value to satisfy the $\mathrm{B}-\mathrm{K}$ fracture criterion decreases to a value of $30 \mathrm{psi}$ at $2500^{\circ} \mathrm{F}$ and becomes right-tip dominated. Comparison of the stable defect regions identified in Figures 13 and 15 reveals that Case -2.5 is a more limiting case.

\section{Case -1.5 Response:}

The next case to examine is Case -1.5 that has the left substrate defect tip within the acreage region and the right tip down the joggle as shown in Figure 7. In this case, both defect tips are approximately the same horizontal distance from the joggle shoulder. A summary of the critical entrapped pressures as a function of the elevatedtemperature value is shown in Figure 16 for Case -1.5. The lowest critical entrapped pressure is 240 psi for temperatures from RT up to $2000^{\circ} \mathrm{F}$, and the left tip dominates the response. As the temperature increases above $2000^{\circ} \mathrm{F}$, the entrapped pressure value decreases to zero at $2250^{\circ} \mathrm{F}$ to satisfy the B-K fracture criterion, and the response becomes right-tip dominated. Comparison of the stable defect regions identified in Figures 15 and 16 reveals that Case -2.5 is a more limiting case.

\section{Case -0.5 Response:}

The final case to examine is Case -0.5 that has the left substrate defect tip near the joggle shoulder on the acreage side and the right tip is well down the joggle as shown in Figure 7. A summary of the critical entrapped pressures as a function of the elevated-temperature value is shown in Figure 17 for Case -0.5. The lowest critical entrapped pressure is $460 \mathrm{psi}$ for temperatures from room temperature up to $1500^{\circ} \mathrm{F}$, and the right tip dominates the response. As the temperature increases above $1500^{\circ} \mathrm{F}$, the entrapped pressure value to satisfy the B-K fracture criterion decreases to zero at $2500^{\circ} \mathrm{F}$ and becomes left-tip dominated. Note that the left tip is nearest to Location 0 at the joggle shoulder. Comparison of the stable defect regions identified in Figures 15 and 17 reveals that substrate defect Case -2.5 remains as the more limiting combined loading case.

\section{Concluding Remarks}

Plane-strain analyses are performed to determine the influence of subsurface-defect internal pressure loading on the thermo-mechanical fracture mechanics response of a reinforced carbon-carbon slip-side joggle region on the Space Shuttle Orbiter wing-leading-edge panels. Combined thermo-mechanical loading conditions are analyzed using elevated temperatures and uniform entrapped pressure loading on the subsurface defect surfaces. These simulations assume that the pressure due to expanding volatiles and water vapor within the reinforced carbon-carbon can exist, can be trapped and contained as a closed volume, and no venting occurs. The reinforced carbon-carbon slip-side joggle fracture capability for combined thermo-mechanical loads is determined using the BenzeggaghKenane mixed-mode fracture criterion and an assumed $G_{c}$ curve for various mode mixity ratios.

Subsurface defects are assumed to be near the joggle shoulder region, the location where the flat acreage region and curved joggle meet and is defined as Location 0 . The locations are identified by the average craze-crack spacing with negative values in the acreage region and positive values in the joggle region. The results indicate that a stable defect region can be defined for a given defect size and location based on critical entrapped pressure values for various local peak temperatures. These critical pressure values are determined using a mixed-mode fracture criterion. The sensitivity of the critical pressure value to peak temperature is determined and illustrated for a $0.375-$ inch-long substrate defect. The smallest stable defect region is observed for the case where the left tip is at Location -2.5 with reference to the joggle shoulder region and the right tip is at Location +0.5 just beyond the joggle shoulder.

At peak temperatures greater than $1500^{\circ} \mathrm{F}$, low entrapped pressure values can cause a substrate defect along the joggle to become unstable. The critical entrapped pressure values from the present study could be generated by volatiles or water vapor for a closed-volume assumption as suggested in Ref. 4 or even for some permeability values as suggested in Ref. 5. These fracture mechanics results suggest that an entrapped defect pressure combined with 
local elevated temperatures has the potential to cause catastrophic subsurface defect growth. For this anomaly to occur, however, several unusual circumstances would be required making such a response plausible although unlikely.

\section{References}

1. Gehman, H. W., Jr.; et al.: Columbia Accident Investigation Board (CAIB) Report. Volume 1, August 2003.

2. Gordon, M. P.: Leading Edge Structural Subsystem and Reinforced Carbon-Carbon Reference Manual. Boeing Orbiter Engineering, Report No. KSC-KLO-98-008, October 19, 1998.

3. Kerr, J.; et al.: Likely Mechanism and Contributors to the Root-Cause for Orbiter Wing-Leading-Edge Joggle RCC SiC Coating Spallation. NASA TM to appear in 2011.

4. Jacobson, N.; and Curry, D.: Internal Pressure as a Possible Contributor to Root Cause of Coating/Substrate Separations in Joggle Region of the Orbiter Wing Leading Edge. NASA/TM-2010216093, January 2010.

5. Stokes, E. H.: RCC Permeability and Coating Strength. Southern Research Institute, Birmingham, Alabama, November 2008.

6. Knight, N. F., Jr.; Raju, I. S.; and Song, K.: Influence of Entrapped Pressure on Thermo-Mechanical Fracture Mechanics Response of Reinforced Carbon-Carbon with Subsurface Defects. NASA/TM-2010215927, February 2010.

7. Knight, N. F., Jr.; Song, K.; and Raju, I. S.: “Space Shuttle Orbiter Wing-Leading-Edge Panel ThermoMechanical Analysis for Entry Conditions,” AIAA Paper No. 2010-2688, April 2010.

8. Knight, N. F., Jr.; Song, K.; and Raju, I. S.: Factors Influencing Thermo-Mechanical Elastic Response of Slip-Side Joggle Regions of the Space Shuttle Orbiter Wing-Leading-Edge Panels. NASA/TM-2010215926, February 2010.

9. Raju, I. S.; Song, K.; Knight, N. F., Jr.; and Phillips, D. R.: Fracture Mechanics Analyses of the Slip-Side Joggle Region of the Space Shuttle Orbiter Wing-Leading-Edge RCC Panels. NASA/TM-2010-215922, February 2010.

10. Anon.: ABAQUS/Standard User's Manuals, Version 6.8. Dassault Systèmes Simulia Corp., Providence, Rhode Island, 2008.

11. Squire, M. D.: Reinforced Carbon-Carbon (RCC) Material Properties Used by the RCC Silicon Carbide Spallation Team. NASA/TM-2010-216713, June 2010.

12. Rybicki, E. F.; and Kanninen, M. F.: "Finite Element Calculation of Stress Intensity Factors by a Modified Crack Closure Integral.” Engineering Fracture Mechanics, Vol. 9, 1977, pp. 931-938.

13. Raju, I. S.: "Calculation of Strain Energy Release Rates with Higher Order and Singular Finite Elements." Engineering Fracture Mechanics, Vol. 28, 1987, pp. 251-274.

14. Krueger, R.: The Virtual Crack Closure Technique: History Approach and Applications. NASA/CR-2002211628, April 2002. Also available in ASME Applied Mechanics Reviews, Vol. 57, No. 2, March 2004, pp. 109-143. 
15. Benzeggagh, M. L.; and Kenane, M.: "Measurement of Mixed-Mode Delamination Fracture Toughness of Unidirectional Glass/Epoxy Composites with Mixed-Mode Bending Apparatus.” Composites Science and Technology, Vol. 56, No. 4, 1996, pp. 439-449.

16. O'Brien, T. K.: Interlaminar Fracture Toughness Testing of RCC and SiC/RCC Interface. NASA/TM2010-216187, January 2010.

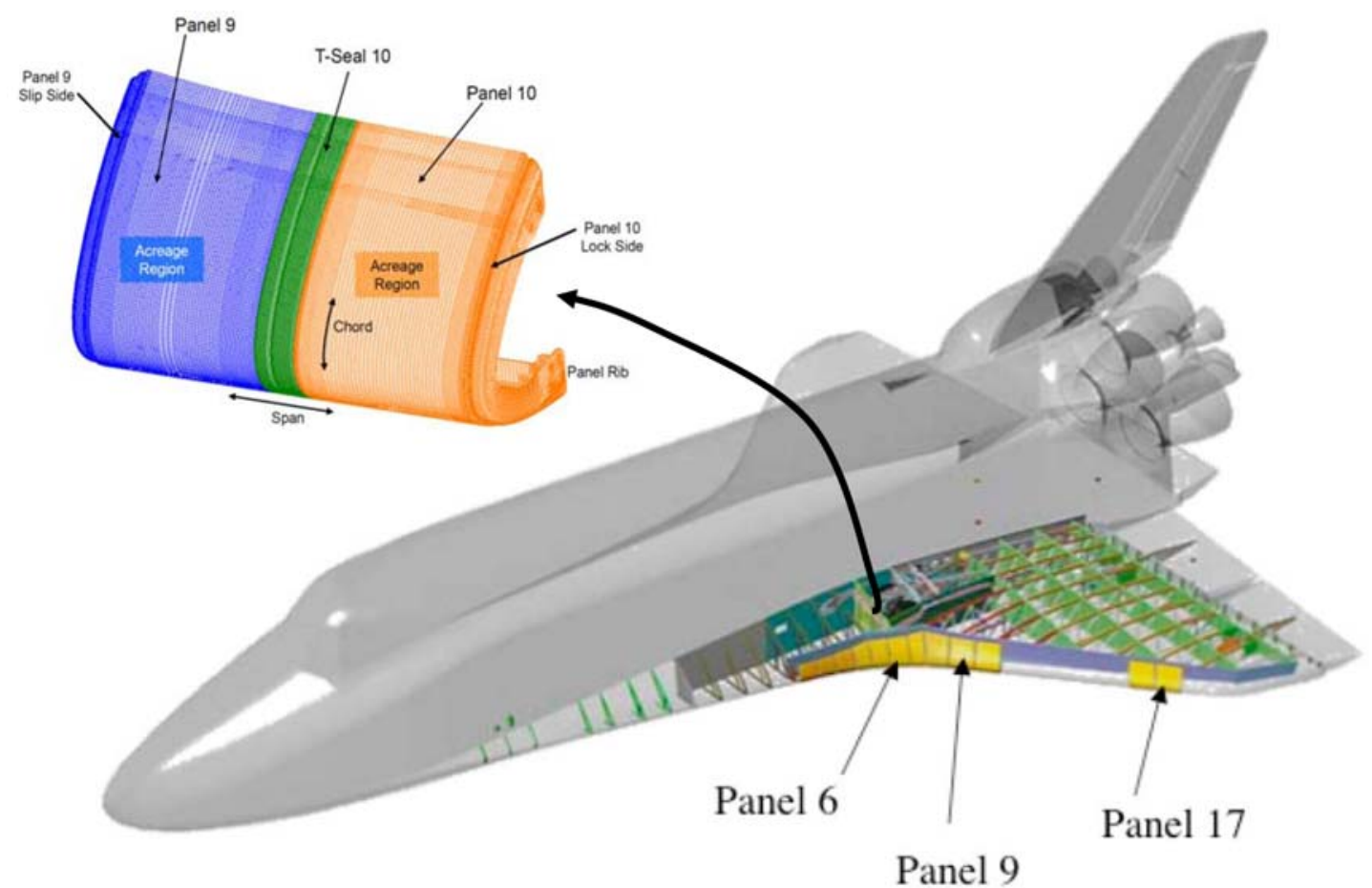

Figure 1. Space Shuttle Orbiter and WLE cut-away view.

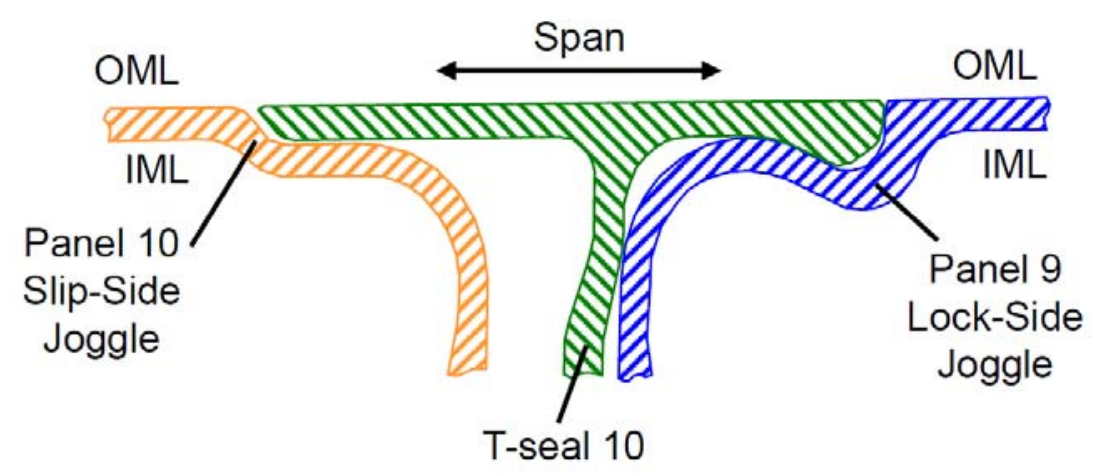

Figure 2. Cross-sectional view of adjacent WLE panels and T-seal.

American Institute of Aeronautics and Astronautics 


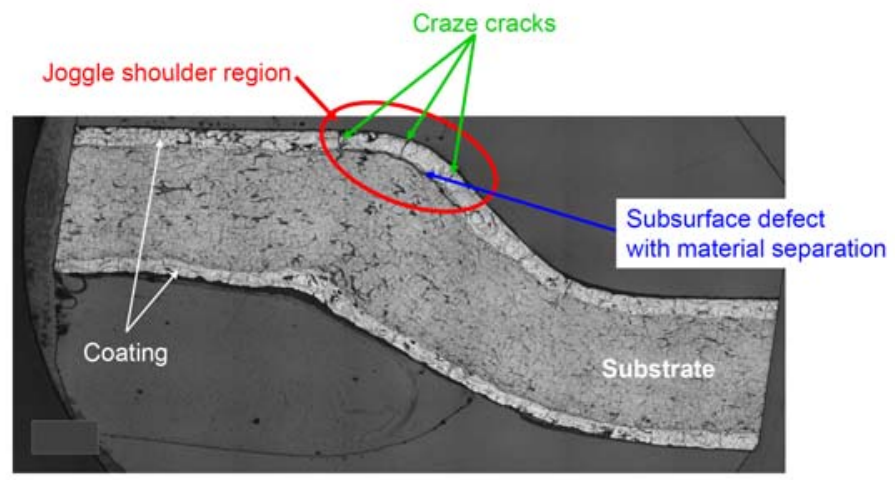

Figure 3. Close-up view of typical slip-side joggle region of an RCC WLE panel (Courtesy of E. Opila, NASA Glenn Research Center).

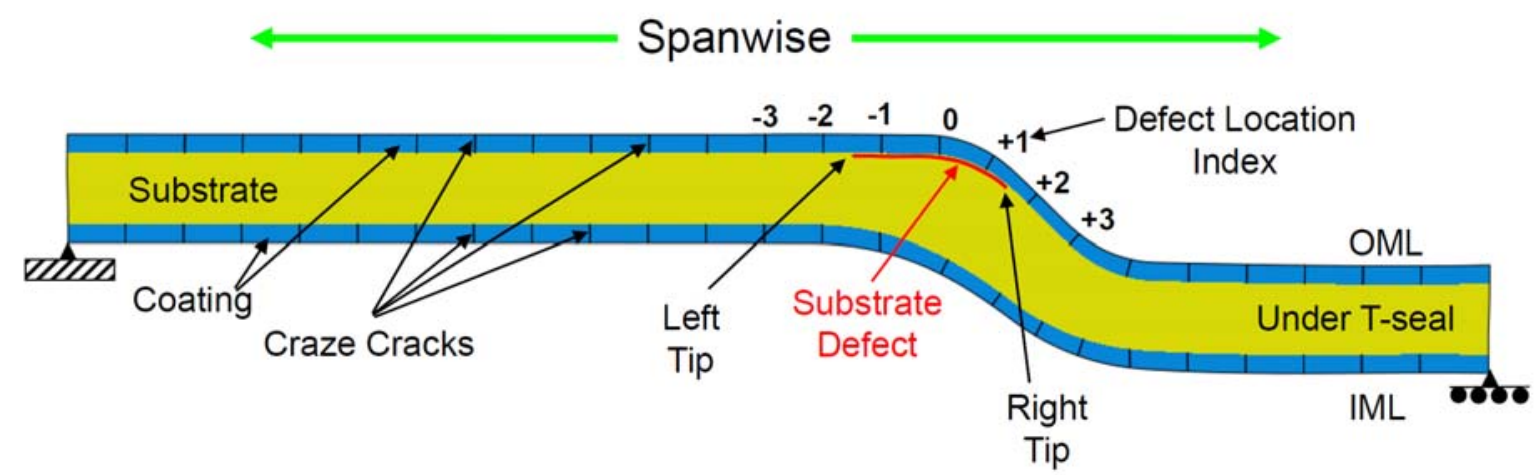

Figure 4. WLE panel slip-side joggle configuration and nomenclature.

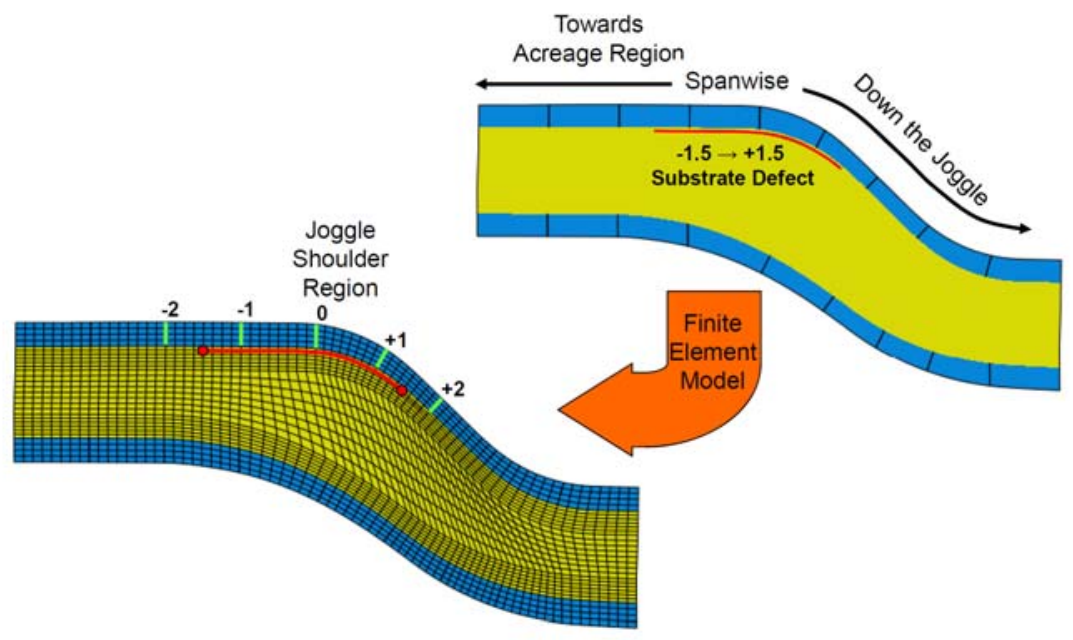

Figure 5. Plane-strain model of slip-side joggle region. 


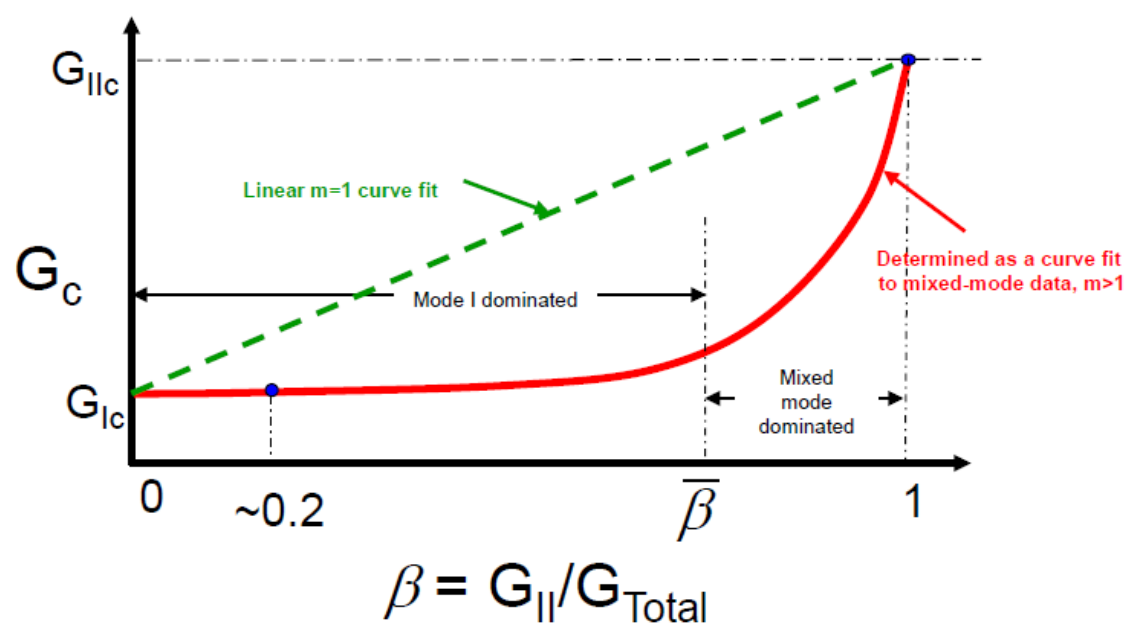

Figure 6. Typical curve fit of mixed-mode fracture data.
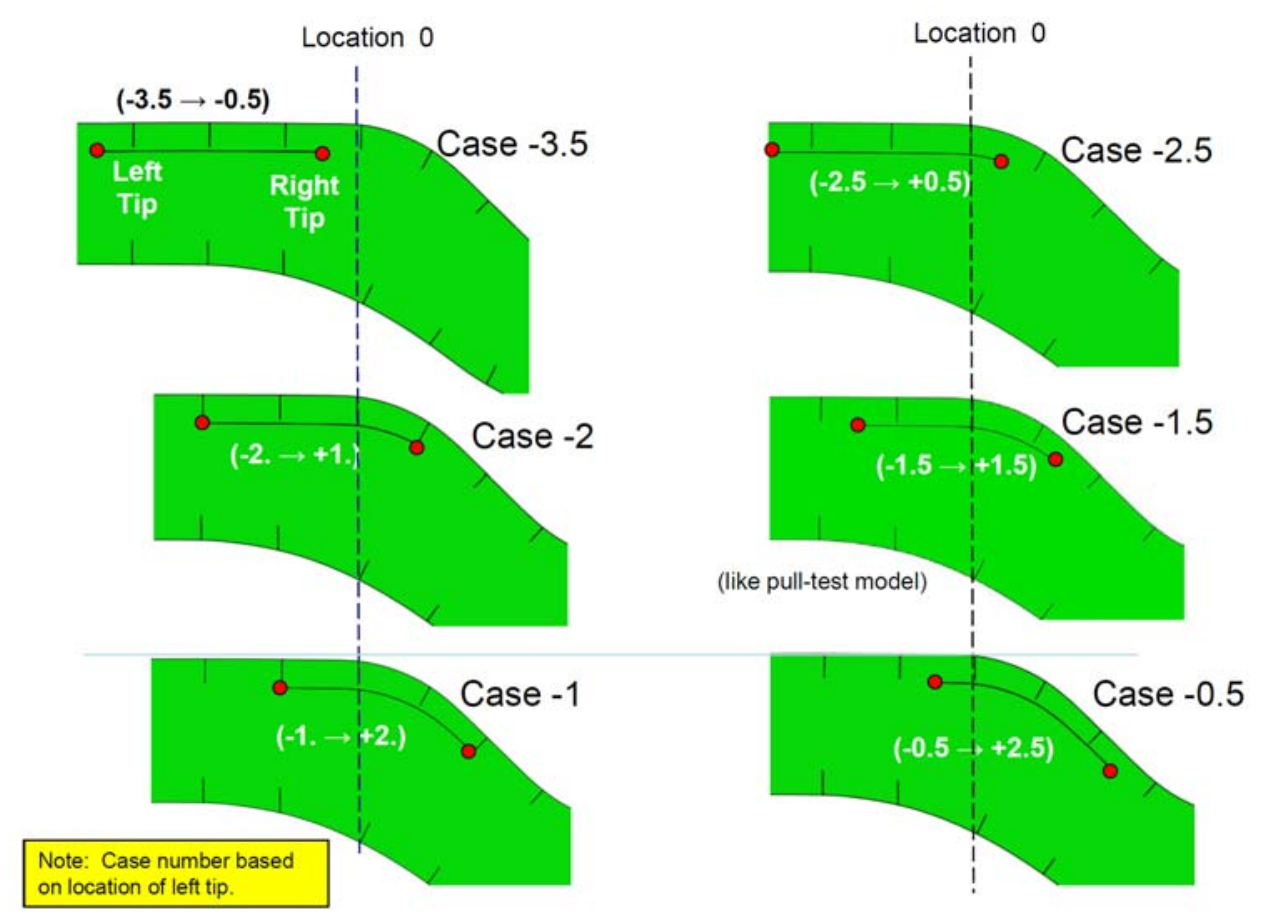

Figure 7. Various 0.375-inch-long substrate defect spanwise locations along joggle. Case number refers to the location of the left tip. 


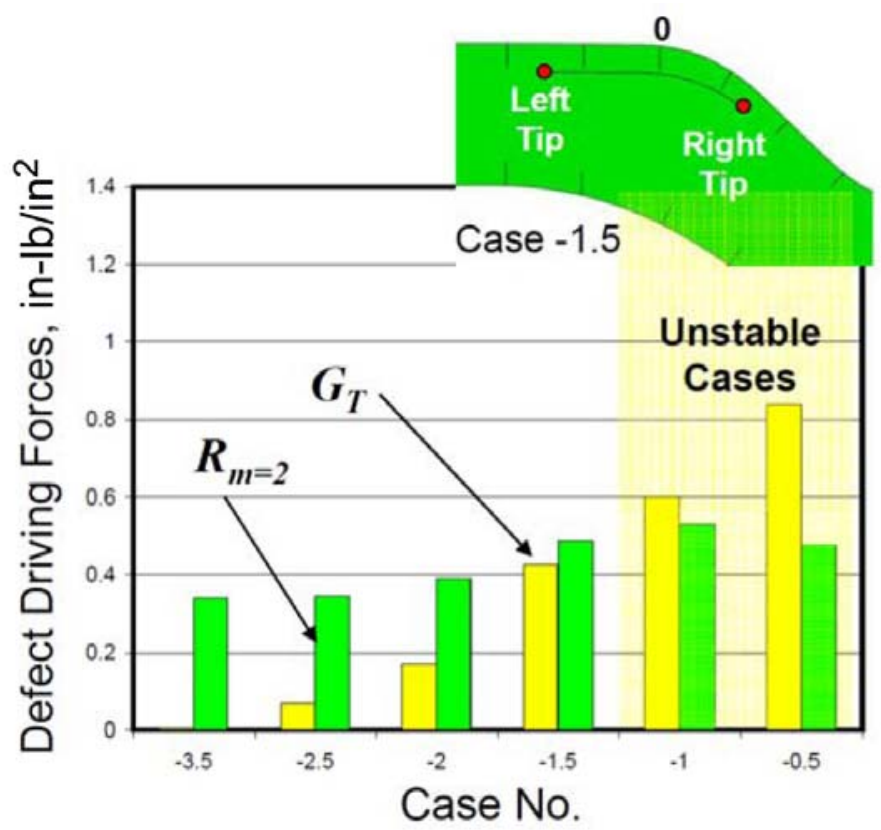

(a) Left tip.

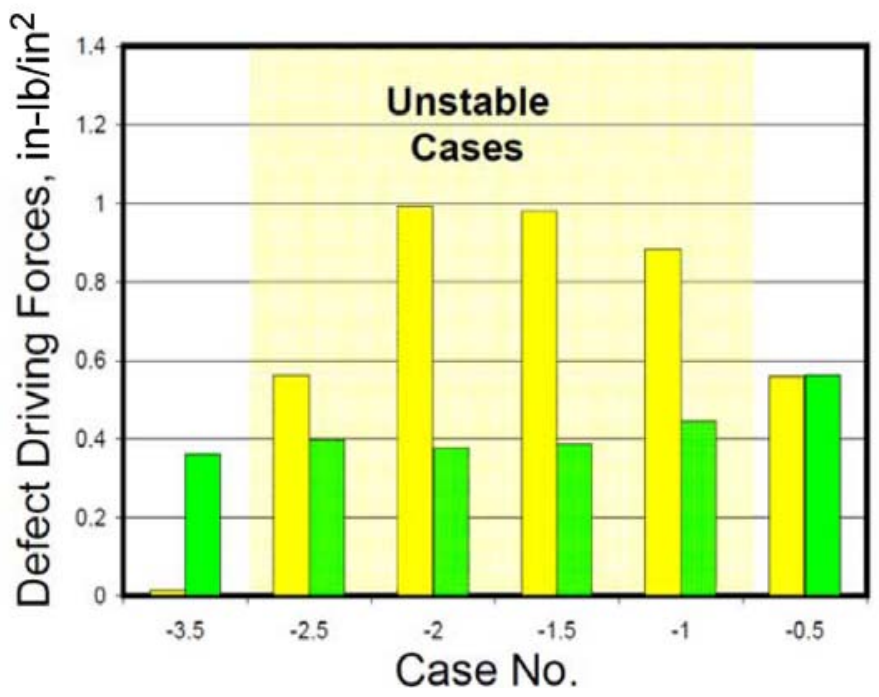

(b) Right tip.

Figure 8. Mixed-mode fracture criterion evaluation for 0.375-inch-long substrate defect at different spanwise locations along the joggle: peak temperature of $2900^{\circ} \mathrm{F}$; zero entrapped pressure; SFT of $1350^{\circ} \mathrm{F}$; B-basis fracture toughness values. 


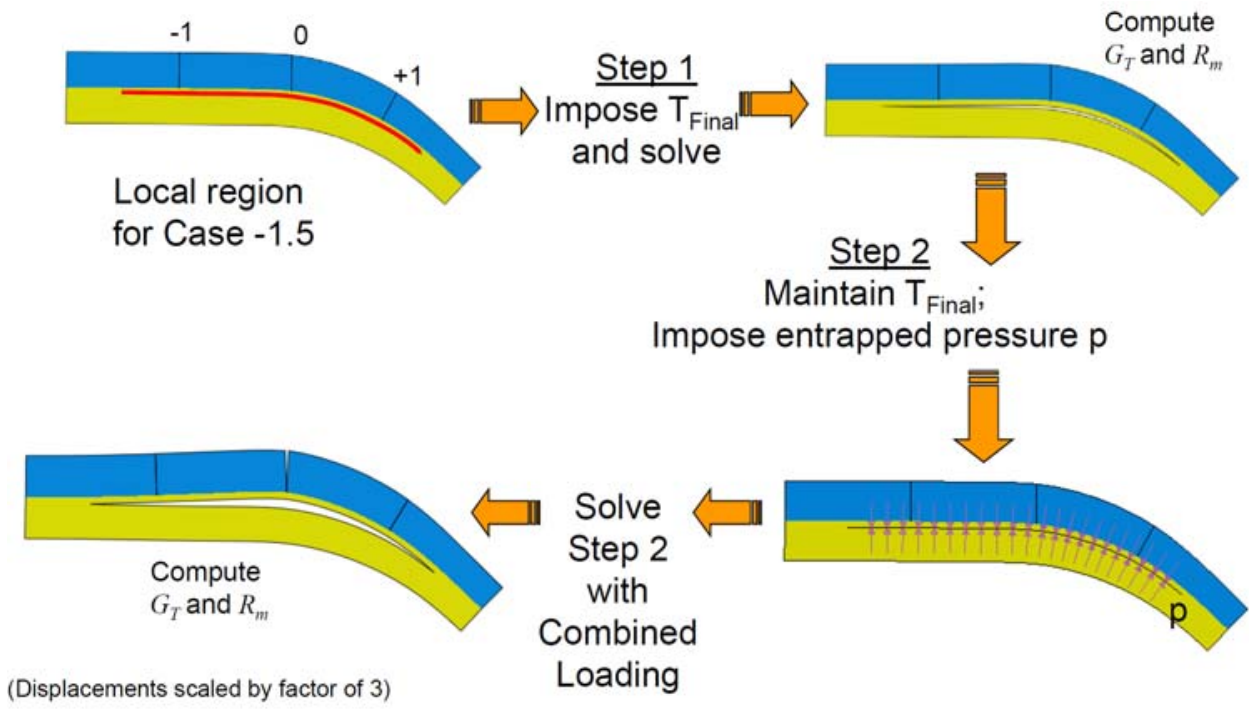

(a) Schematic of two-step analysis process showing only a portion of the OML joggle region.

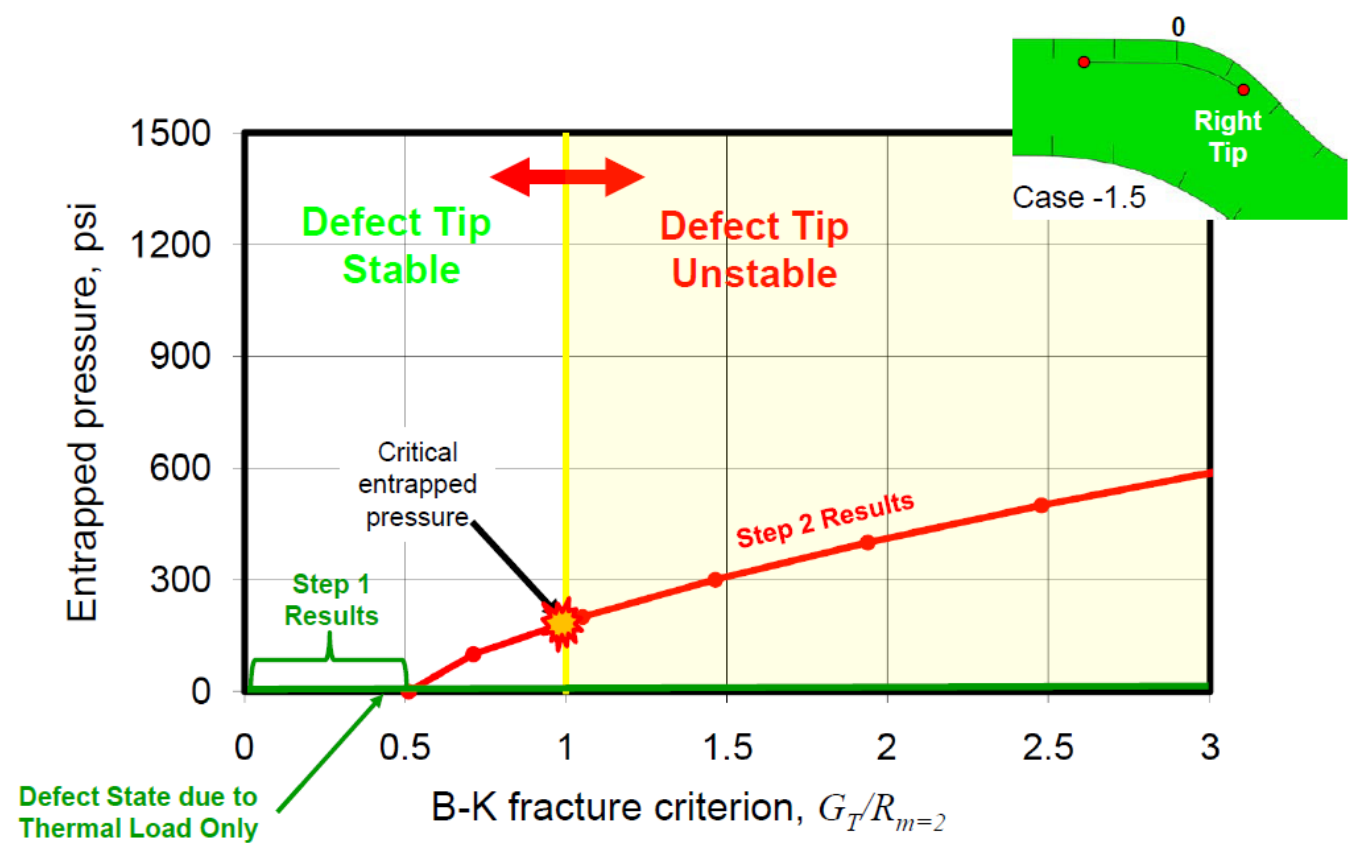

(b) Anticipated typical results from two-step process.

Figure 9. Illustration of the two-step analysis process and anticipated results for a combined thermal and entrapped pressure loading condition. 


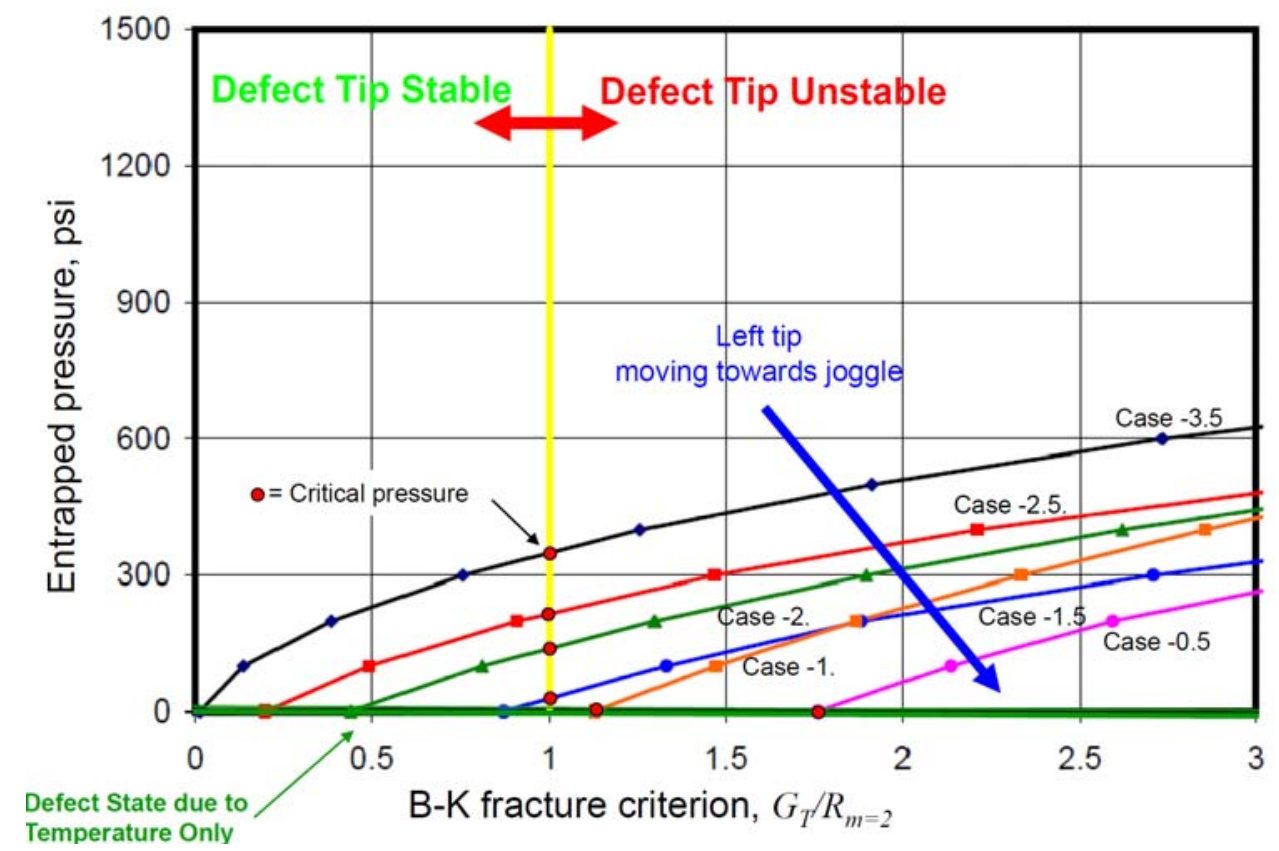

(a) Left tip.

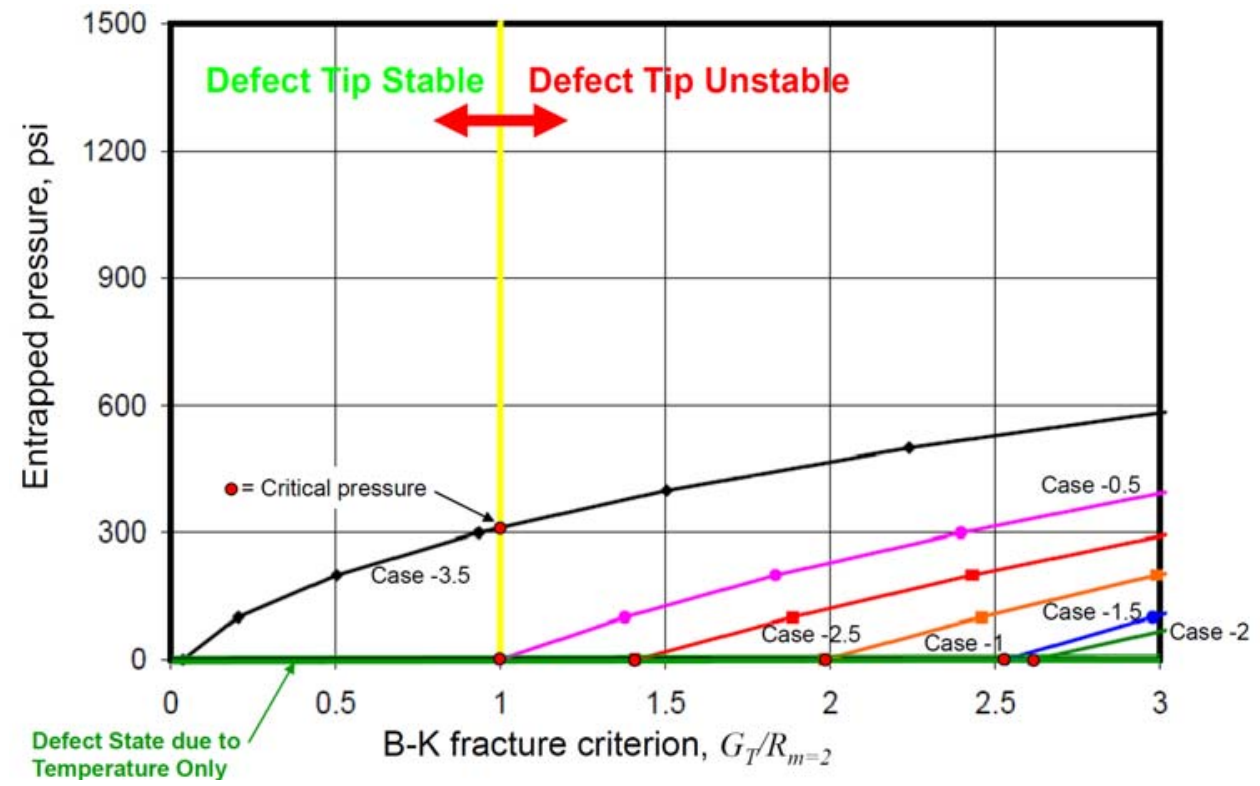

(b) Right tip.

Figure 10. Influence of entrapped pressure and defect spanwise location on the fracture response of a 0.375-inch-long substrate defect under peak-heating entry temperature condition: peak temperature of $2900^{\circ} \mathrm{F}$; SFT of $1350^{\circ} \mathrm{F}$; B-basis fracture toughness values.

American Institute of Aeronautics and Astronautics 


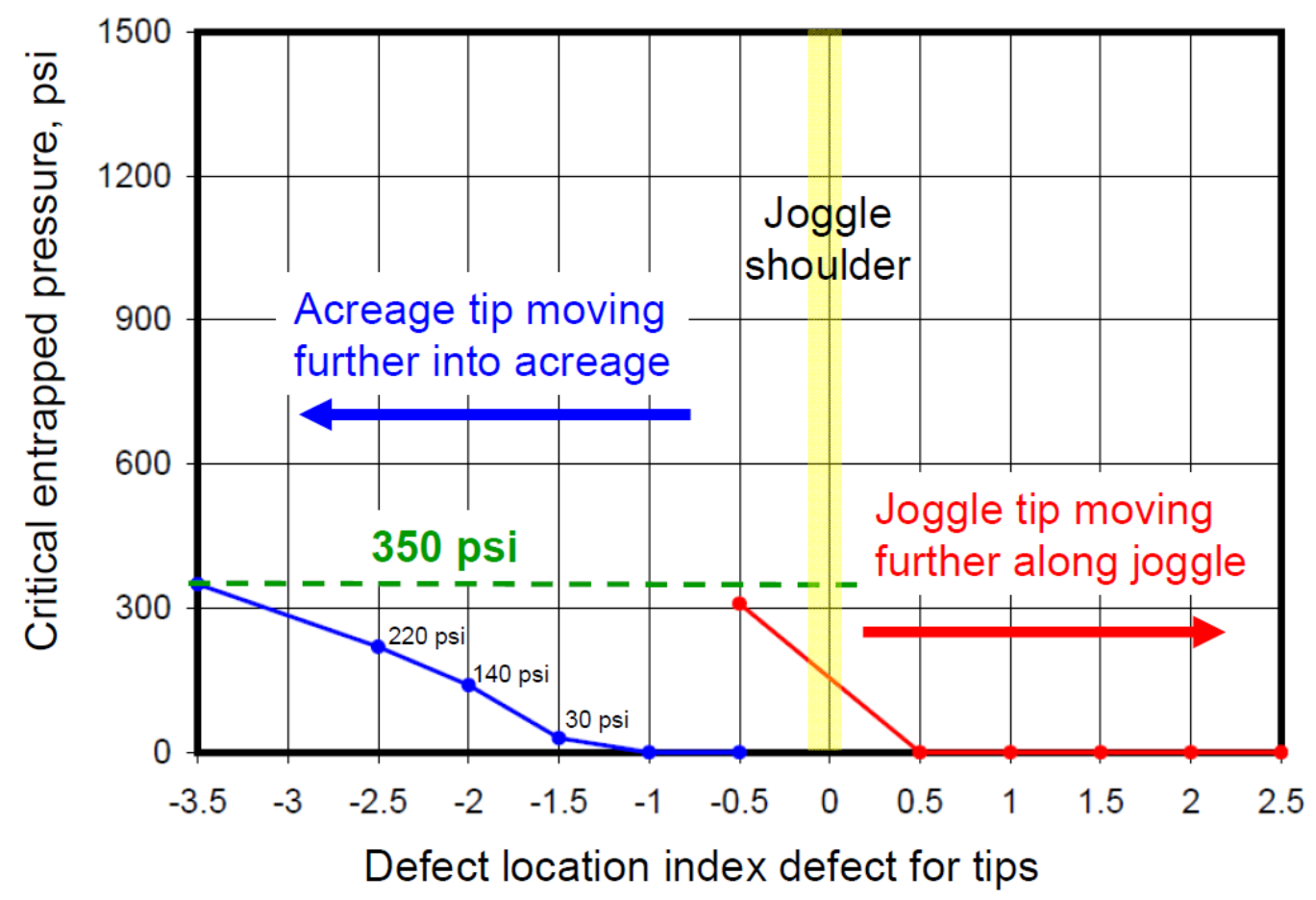

Figure 11. Effect of defect spanwise location on the critical entrapped pressure at peak-heating entry temperature condition: peak temperature of $2900^{\circ} \mathrm{F}$; SFT of $1350^{\circ} \mathrm{F}$; B-basis fracture toughness values. 


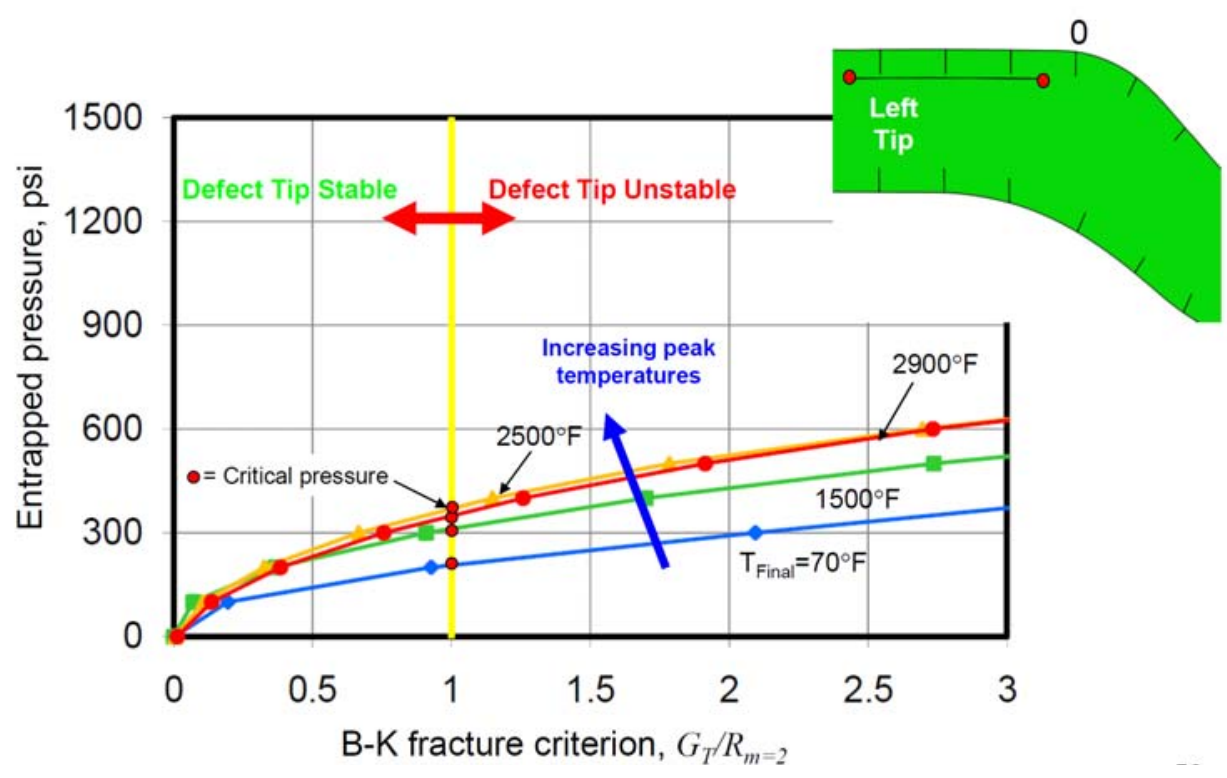

(a) Left tip at Location -3.5.

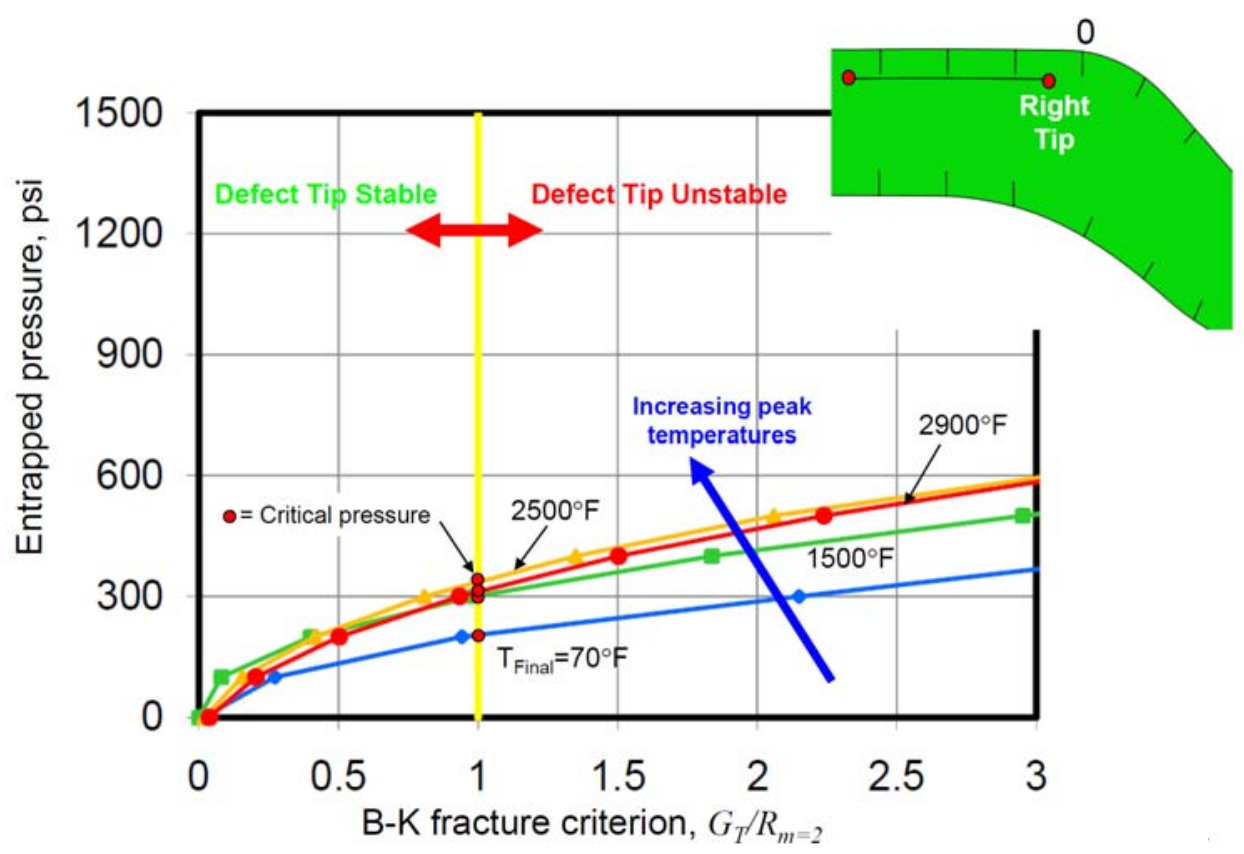

(b) Right tip at Location -0.5 .

Figure 12. Influence of entrapped pressure on the fracture response of Case -3.5 for elevated-temperature conditions: SFT of $1350^{\circ} \mathrm{F}$; B-basis fracture toughness values. 


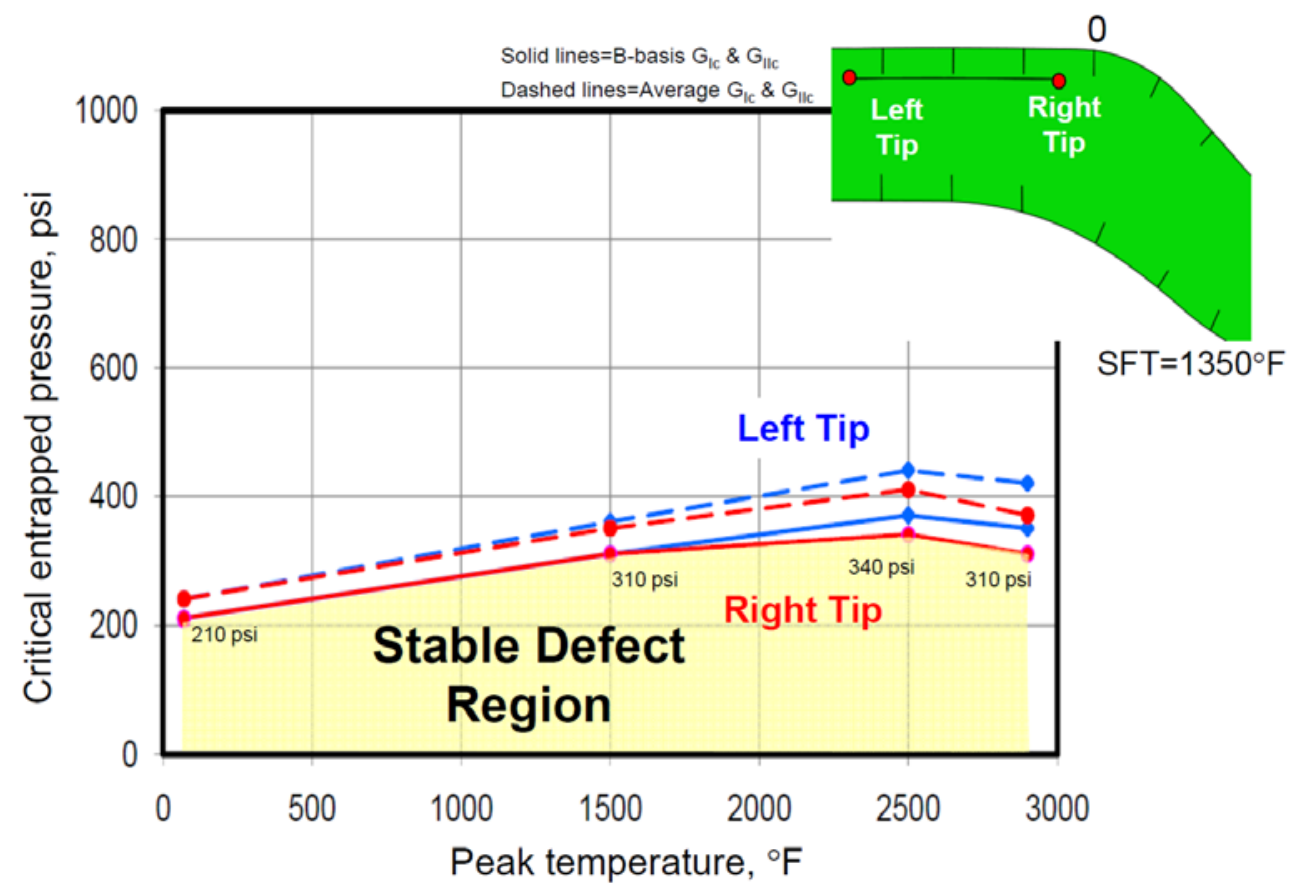

Figure 13. Determination of stable defect region for Case -3.5 for combined elevated-temperature and entrapped pressure conditions: SFT of $1350^{\circ} \mathrm{F}$; B-basis and average fracture toughness values. 


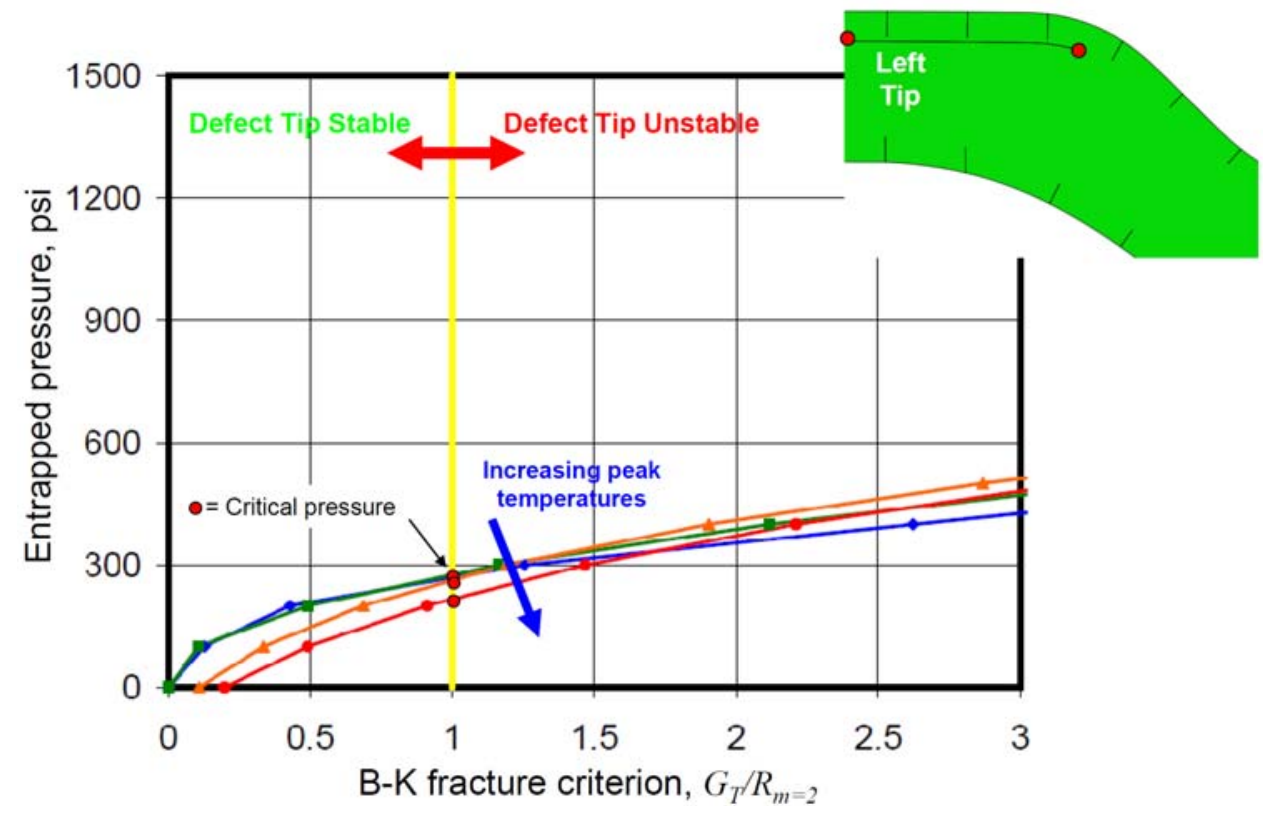

(a) Left tip at Location -2.5 .

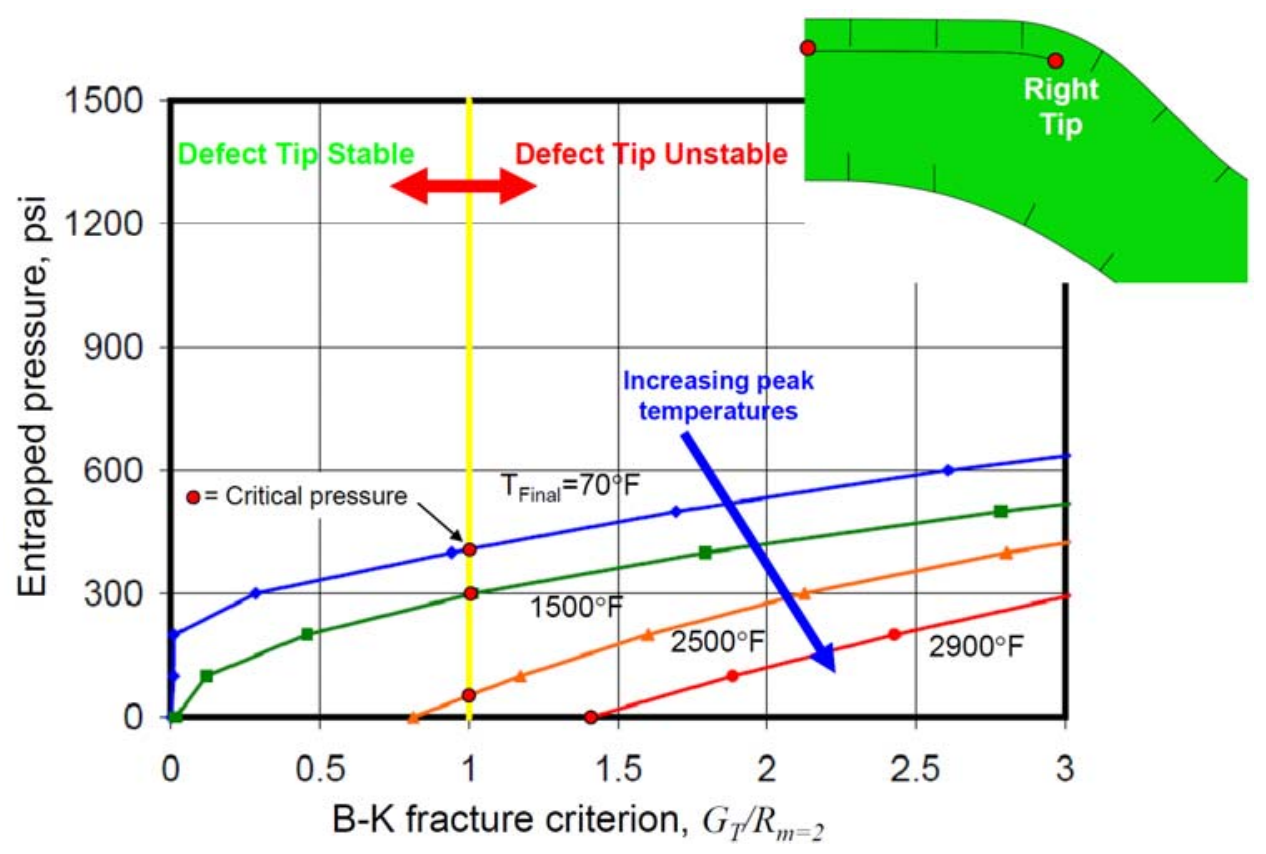

(b) Right tip at Location +0.5 .

Figure 14. Influence of entrapped pressure on the fracture response of Case -2.5 for elevated-temperature conditions: SFT of $1350^{\circ} \mathrm{F}$; B-basis fracture toughness values. 


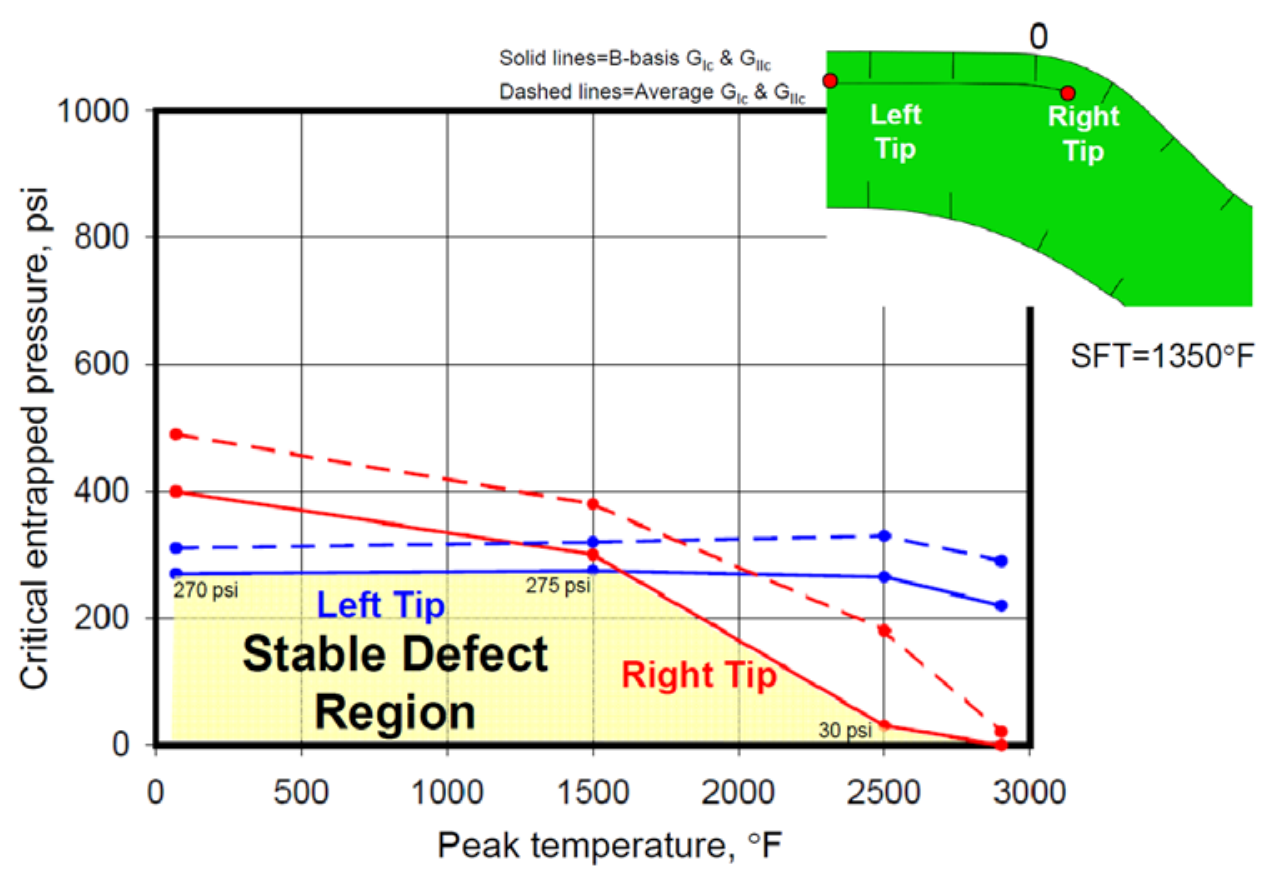

Figure 15. Determination of stable defect region for Case -2.5 for combined elevated-temperature and entrapped pressure conditions: SFT of $1350^{\circ} \mathrm{F}$; B-basis and average fracture toughness values.

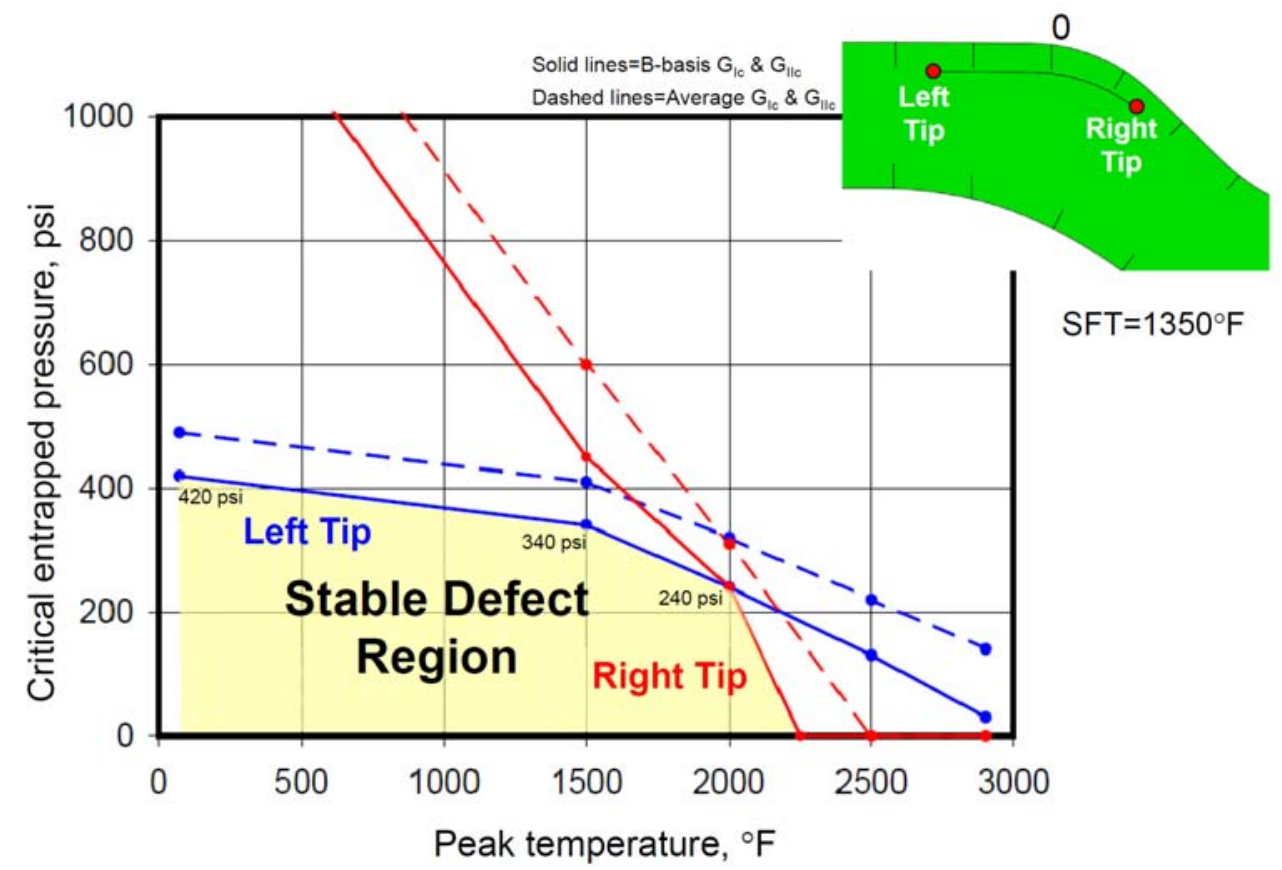

Figure 16. Determination of stable defect region for Case -1.5 for combined elevated-temperature and entrapped pressure conditions: SFT of $1350^{\circ} \mathrm{F}$; B-basis and average fracture toughness values. 


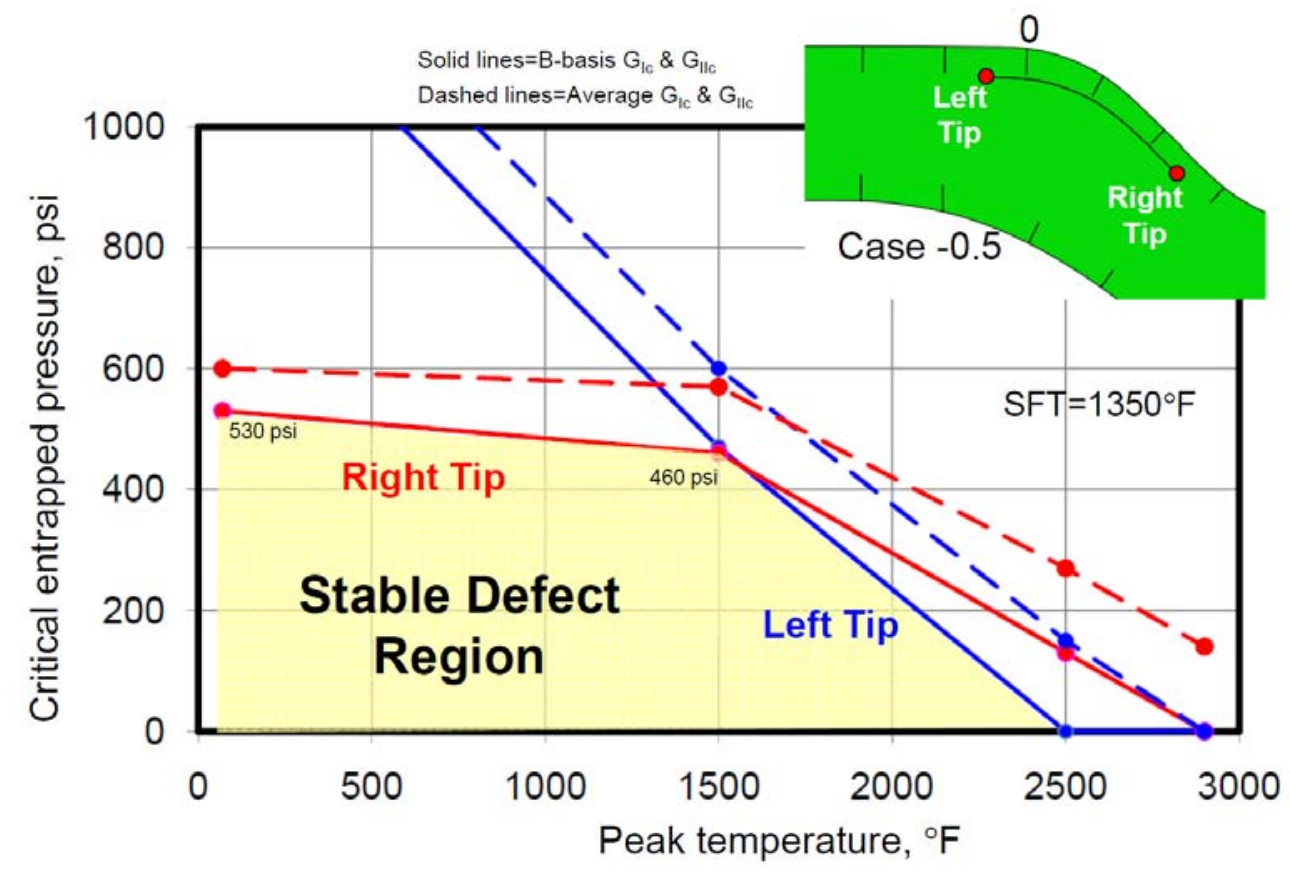

Figure 17. Determination of stable defect region for Case -0.5 for combined elevated-temperature and entrapped pressure conditions: SFT of $1350^{\circ} \mathrm{F}$; B-basis and average fracture toughness values. 